\title{
A (NÃO) CONCRETIZAÇÃO DO PRINCÍPIO DA PRECAUÇÃO PELOS TRIBUNAIS INTERNACIONAIS
}

\section{LA (NO) PUESTA EN PRÁCTICA DEL PRINCIPIO DE PRECAUCIÓN POR LOS TRIBUNALES INTERNACIONALES}

\section{Ana Cristina Paulo Pereira ${ }^{1}$}

Resumo: Criado com a finalidade de evitar danos graves $e$ irreparáveis ao meio ambiente ou à saúde, o princípio da precaução incide quando há insuficiência de dados científicos conclusivos acerca da ocorrência desse dano ou de sua extensão. O princípio sofre da ausência de unanimidade na doutrina e na jurisprudência internacional quanto ao seu verdadeiro status jurídico, além de confrontar-se com outros princípios mais antigos do direito internacional público. Por outro lado, seu caráter abstrato e genérico faz com que tribunais internacionais, inclusive os que pertencem a áreas de integração regionais, hesitem em extrair-lhe uma obrigação concreta para os Estados. A aplicação efetiva do princípio da precaução por esses tribunais é o objetivo maior do presente trabalho.

Resumen: Creado con el fin de evitar perjuicios graves e irreparables para el medio ambiente o la salud, el principio de precaución actúa cuando no hay suficientes datos científicos concluyentes sobre la ocurrencia de estos daños o su extensión. El principio padece de la falta de unanimidad en la doctrina y la jurisprudencia internacional con respecto a su status jurídico actual y aún tiene que hacer frente a otros principios más antiguos del derecho internacional público. Por otra parte, su carácter abstracto y genérico no favorece a que los tribunales internacionales, incluso los pertenecientes a las áreas de integración regional, se lo consigne una obligación específica para los Estados. La aplicación efectiva del principio de precaución en estas cortes es el tema central de este trabajo.

Palavras-chave: Princípio da precaução, Obrigação de nãocausar danos transfronteiriços, Status jurídico dos princípios do direito internacional do meio ambiente, Jurisprudência internacional sobre meio ambiente

1 Professora Associada da Faculdade de Direito da Universidade do Estado do Rio de Janeiro (UERJ) e Professora Adjunta do Instituto Brasileiro de Mercados de Capitais (IBMECRJ), Curso de Relações Internacionais. 
Palabras clave: Principio de precaución, Obligación de no crear daño transfronterizo, Status jurídico de los principios del derecho internacional del medio ambiente, Jurisprudencia internacional en medio ambiente

\section{Introdução}

De acordo com Jonas Ebbesson (2009, p. 1)

padrões, princípios e procedimentos para a proteção do meio ambiente são geralmente instrumentos para alcançar, digase, a conservação de ecossistemas frágeis e espécies ameaçadas, a preservação da água fresca e de outros recursos naturais, a restauração de solos contaminados bem como da camada de ozônio, e a proteção da saúde humana. Essa concepção de objetivo orientado é evidente não só no direito interno como no direito internacional (tradução nossa).

O princípio da precaução foi construído, portanto, com vistas a alcançar esses objetivos, eis que, em última análise, visa a evitar o dano muito mais do que repará-lo, mais ainda porque o dano, ao meio ambiente, na maioria das vezes, é irreparável.

Embora o princípio da precaução tenha origem no direito internacional do meio ambiente, sendo um de seus pilares, seu âmbito de incidência é muito mais amplo, alcançando também à saúde humana, animal e vegetal.

Por outro lado, o princípio da precaução não age isoladamente, mas de forma articulada com outros conceitos úteis do direito internacional do meio ambiente, tais como: o do desenvolvimento sustentável, da equidade e da integridade territorial: mais especificamente, o princípio pode ser a base para a concretização da noção da equidade inter-gerações, na medida em que propugna pela obrigação da geração presente de zelar e velar pelo planeta, mantendo sua integridade para as gerações futuras e garantido a sobrevivência da espécie humana, conforme Ebbesson (2009, p. 9).

É preciso ter em mente que precaução e prevenção não se confundem, embora os dois termos possam estar interligados, como explicaremos mais adiante. No momento, basta dizer que a precaução 
atua quando há ausência de prova científica conclusiva acerca de um determinado dano irreversível e grave ao meio ambiente ou à saúde, já a prevenção, esta atua na iminência de dano específico. Em suma: na precaução predomina o elemento dúvida, enquanto na prevenção o da certeza, mas em ambos os casos o Estado ver-se-ia forçado a adotar uma conduta capaz de evitar o dano ou, no mínimo, minimizar seus efeitos, dependendo dos riscos envolvidos.

A origem do princípio da precaução como conceito legal remonta à legislação alemã ("vorsorgeprinzip"), de 1976, que retoma os termos da Declaração de Wingspread de 1970, conforme informa Schrijver (2008, p. 184). Quanto à sua primeira formulação internacional de forma expressa, vamos encontrá-la na $1^{\text {a }}$ Conferência Internacional sobre a Proteção do Mar do Norte, de 1984, tendo sido reforçado na conferência de 1987 e, em seguida, reafirmado em outros tratados e declarações internacionais, como ensina Cretella Neto (2012, p. 225). A título de exemplo citamos: a Declaração de Bergen, 1992 (parágrafo 7); a Declaração do Rio, 1992 (Princípio 15); a Convenção sobre a Diversidade Biológica, 1992 (Preâmbulo, parágrafo 9); Acordo sobre a Implementação dos Dispositivos da Convenção do Mar de 1992 concernentes à Conservação e Exploração de População de Peixes Transzonais e Peixes Altamente Migradores, 1995 (Artigo 6); e o Protocolo de Cartágena sobre Biosegurança, 2000 (Artigos 1, 10 e 11).

Apesar da aparente aceitação do princípio da precaução no âmbito internacional, forçoso é constatar que sua aplicação concreta pelos diferentes tribunais internacionais ainda carece de interpretação uniforme ou, pelo menos, harmoniosa. Importa-nos, portanto, entender a que se deve essa oscilação jurisprudencial.

A nosso ver, dois aspectos poderiam contribuir para enfraquecer o princípio da precaução, retirando-lhe a efetividade pretendida. Primeiramente, a própria dúvida quanto ao seu verdadeiro status jurídico: seria um princípio de direito internacional, fonte de obrigação para os Estados, ou simples abordagem ou enfoque ${ }^{2}$ Em segundo lugar, sua oposição a princípios já consagrados do direito internacional que possuem conotação econômica importante e de conteúdo mais concreto, em contradição ao princípio da precaução de caráter mais abstrato e que atua na inexistência de provas concretas do dano.

Este trabalho pretende analisar o verdadeiro lugar que ocupa o

2 Ciente da divergência doutrinário e jurisprudencial e sem nos posicionarmos sobre uma ou outra corrente, utilizaremos neste trabalho o termo "princípio", eis que esse é o termo usado na sua origem. 
princípio da precaução nas relações inter-estatais, mormente quando estiver em causa a proteção do meio ambiente ou da saúde.

Em um primeiro momento, retomaremos os questionamentos acima suscitados, utilizando a doutrina e, principalmente, as decisões prolatadas de modo geral por alguns tribunais internacionais que tiveram a oportunidade de se manifestar, ainda que indiretamente, sobre o princípio da precaução.

Em um segundo momento, observaremos os entendimentos expressos de tribunais regionais que funcionam dentro de sistemas de integração econômica, nomeadamente do Tribunal de Justiça da União Européia (TJUE) e dos Tribunais Arbitrais Ad Hoc (TAH) e Tribunal Permanente de Revisão que atuam no mecanismo de solução de controvérsias do Mercosul.

Ao final, esperamos ser capazes de nos posicionarmos e contribuir com uma resposta acerca da real efetividade do princípio da precaução em seu estágio atual. Estamos conscientes de que o tema envolve prioridades, conflitos e confrontos de interesses, ultrapassando a clássica relação Estado-Estado para alcançar a sociedade civil como um todo.

\section{Parte I: Obstáculos à concretização do Princípio da Precaução}

O princípio da precaução veio à luz em vários julgados realizados por alguns dos mais importantes tribunais internacionais da atualidade, mormente para justificar condutas contrárias a obrigações assumidas pelos Estados no âmbito internacional, com base na excludente da necessidade ambiental ou segurança pública quando se trata de proteção da saúde.

Que o meio ambiente vem sendo preocupação constante desses tribunais é uma verdade irrefutável: todos são unânimes em declarar a importância de preservar o meio ambiente para gerações presentes e futuras. Porém, quando se trata de dar efetividade ao princípio da precaução, um dos princípios do direito internacional do meio ambiente, deparamo-nos com uma situação distinta: algumas vezes o princípio é relegado a um segundo plano, servindo apenas como elemento subsidiário, subtraído da autoridade de um autêntico princípio de direito internacional; outras vezes, o princípio cede lugar a outros mais tradicionais e caros aos Estados, os quais buscam na exploração de seus recursos naturais um meio de promover seu desenvolvimento econômico. 


\section{1) A incerteza quanto à autoridade do princípio da precaução enquanto autêntico princípio de direito internacional}

Enquanto a doutrina debate sobre o real status jurídico do princípio da precaução, a jurisprudência internacional, por sua vez, hesita em lhe atribuir valoração clara e precisa: pode-se dizer que o mais perto que um tribunal internacional chegou sobre o status do direito internacional do meio ambiente como um todo ocorreu em 2005, quando do julgamento pela Corte Permanente de Arbitragem (CPA) do caso Iron Rhine ("IJzeren Rijn”).

Com efeito, no referido caso, a CPA, sem esclarecer o que no direito internacional do meio ambiente constitui "as regras ou princípios ou ainda o soft law, e quais tratados ou princípios contribuíram para o desenvolvimento do direito internacional consuetudinário", declarou que...

Environmental law and the law on development stand not as alternative but as mutually reinforcing, integral concepts, which require that where development may cause significant harm to the environment there is a duty to prevent, or at least mitigate, such harm. This duty, in the opinion of the Tribunal, has now become a principle of general international law ${ }^{3}$.

A dúvida doutrinária reside em saber se o princípio da precaução é um princípio do direito internacional nos termos do Artigo 38 do Estatuto da Corte Internacional de Justiça de 1945, ou simplesmente se trata de um enfoque, uma abordagem, a ser seguido quando da conduta estatal relacionada a questões de meio ambiente ou de saúde pública.

A questão torna-se ainda mais pertinente em se tratando do direito internacional do meio ambiente, eis que, conforme afirma Kiss e Shelton (2007, p. 89), os princípios estão presentes nesse ramo, mais do que em qualquer outro do direito internacional geral.

Conforme informa Rebecca Bratspies (2006, pp. 156-157), os EUA, por exemplo, preferem adotar um sistema regulatório baseado em avaliação quantitativa de risco, ou seja, em extensiva prova de que há risco, do que no princípio da precaução, o qual, para as autoridades norte-americanas, é "tão mítico quanto a figura do unicórnio". O princípio seria sobretudo uma forma de encarar as coisas, significando apenas "take care" ou "better safe than sorry".

3 Rhine ("IJzeren Rijn") Railway Arbitration (Belgium v. The Netherlands), Award of the Arbitral Tribunal, 24 may 2005, paras. 58-59. Disponível em: http://www.pca-cpa.org 
Obviamente, essa abordagem não nos parece representar a vontade do legislador originário ao vislumbrar o princípio da precaução como um dos integrantes do corpus juris do direito internacional do meio ambiente, sendo imprescindível para alcançar o fim a que este se pretende.

Nesse sentido, expressam Kiss e Shelton (2007, p. 94) que a proclamação do princípio da precaução pode ser considerada uma das mais importantes disposições da Declaração do Rio de 1992, conforme expresso em seu Princípio 15...

In order to protect the environment, the precautionary principle shall be widely applied by States according to their capabilities. Where there are threats of serious or irreversible damage, lack of full scientific certainty shall not be use as a reason for postponing costeffective measures to prevent environmental degradation.

A verdade é que, para que o princípio da precaução seja considerado fonte válida de obrigação para os Estados deve possuir características que o permitam integrar uma das categorias previstas no artigo 38 do Estatuto da CIJ, constituindo norma convencional, costumeira ou princípio geral do direito internacional reconhecido pelas nações civilizadas, conforme curiosa expressão usada no referido dispositivo.

Convém, entretanto, uma explicação prévia acerca dos princípios, eis que, embora figurem como fonte do direito internacional no Artigo 38 do Estatuto da Corte, compartilhamos da posição de alguns doutrinadores de que os princípios não são propriamente fonte do direito internacional, mas sim normas com características próprias (conteúdo abstrato/valorativo/abrangente), que se extraem seja do direito costumeiro - o mais comum - ou de tratado ou convenção internacional. Nesse sentido, Benedetto Conforti expressa que os princípios gerais do direito não são mais do que uma categoria sui generis de norma consuetudinária internacional (apud Cretella Neto, 2012, p. 208).

Em que pese a alegada falta de autonomia dos princípios enquanto fonte do direito internacional, não resta dúvida quanto às suas características peculiares, que os distinguem das demais normas. Assim sendo, faz-se mister uma análise, ainda que superficial, do real significado do termo "princípio", eis que, a idéia de princípio indica sempre uma função normativa, de modo que não se trata de simples opinião doutrinária ou um conceito abstrato da verdade ou da justiça, 
conforme Vitanyi (1976, p. 537).

Portanto, os princípios são imprescindíveis dentro de um determinado sistema de direito, eis que as regras particulares e específicas desse sistema devem representar a aplicação concreta das idéias por eles expressadas às situações regidas.

Em sentido oposto, M. Ustor, um dos negociadores do projeto de artigos sobre a responsabilidade dos Estados, elaborado pela Comissão de Direito Internacional das Nações Unidas, vê nos princípios motivo de complicação, haja vista os vários significados que possam vir a ter. Por conseguinte, o autor defendia que "em vez de introduzir no texto do projeto uma expressão vaga, seria melhor renunciar sua utilização", tal qual ocorrera com a Convenção de Viena sobre o Direito dos Tratados de 1969 (apud Vitanyi, 1976 p. 536).

Em todo caso, como observa Virally (apud Vitanyi, 1976, p. 537)...

os princípios permanecem sempre sinônimo de regras jurídicas abstratas, fornecedores das bases de um regime jurídico suscetível de se aplicar a múltiplas situações concretas, seja para as regulamentar de maneira permanente, seja para resolver as dificuldades que essas situações engendram (tradução nossa).

Kiss e Shelton (2007, p. 89) vão ainda mais além para atribuir aos princípios quase que a função de um "coringa" em um jogo de cartas. Nesse sentido, os autores expressam que os princípios podem indicar as características essenciais de instituições legais, designar normas legais fundamentais, ou suprir lacunas do direito positivo, servindo, ainda, para orientar e direcionar os rumos desse direito e fornecer-lhe inclusive um ratio, sem necessariamente constituírem, em si mesmos, uma norma vinculante.

Quanto ao princípio da precaução especificamente, não restam dúvidas de que seu caráter abstrato e sua função complementar justificam-se na medida em que informa um valor (o da proteção do meio ambiente e da saúde em caso de dúvida) e permeia todo o direito internacional do meio ambiente, de forma coordenada com os demais princípios desse ramo: o princípio da precaução incidirá sempre que houver potencial risco de dano grave e irreversível.

Porém, essas características não são suficientes para atribuir autoridade normativa ao princípio da precaução; para tanto, deve reverter a forma de norma costumeira internacional, a defeito de não 
estar previsto convencionalmente em um sistema jurídico de alcance bilateral, multilateral ou regional, caso em que não haverá nenhuma dúvida quanto à sua autoridade normativa para as partes contratantes, em que pese possíveis dificuldades quanto à sua interpretação e alcance.

A dificuldade reside no fato de que, se já é difícil no direito internacional clássico identificarmos a existência de um costume, segundo Cretella Neto (2012, p. 198 ), dada as condições estritas para sua formação (basicamente, prática reiterada, por certo tempo, pelos Estados, de uma conduta e a convicção por parte destes da sua obrigatoriedade), mais ainda no sub-ramo do direito internacional do meio ambiente que é muito mais recente.

Entendemos que para chegarmos a alguma conclusão sobre o assunto, devemos abordar o princípio da precaução como parte de um todo indivisível, ou seja, considerando outros princípios do direito internacional do meio ambiente, eis que somente a obrigatoriedade desses engendrará a obrigatoriedade daquele.

Nesse sentido, note-se que a mais intrínseca e importante atuação do princípio da precaução se dá na consecução do princípio da prevenção do dano, visto ser este o próprio objetivo do princípio.

O princípio da prevenção, a seu turno, pressupõe a obrigação do Estado de adotar as "devidas diligências" (due diligence) antes de autorizar uma atividade ou o comércio de um bem potencialmente danoso ao meio ambiente ou à saúde. Em geral, essa devida diligência se traduziria, por exemplo: na exigência de um estudo de impacto ambiental prévio à autorização, na imposição de condições estritas para a realização da atividade e controle constante sobre esta, bem como na existência de meios capazes de julgar as conseqüências de suas eventuais violações; tudo em consonância com os princípios maiores da razoabilidade e da boa fé.

De acordo com Okowa (apud McIntyre, 2007, p. 221), a obrigação substancial do Estado de prevenir danos ao meio ambiente a áreas fora de sua jurisdição pressupõe a obrigação secundária desse Estado de proceder a um estudo de impacto ambiental, ou seja, a devida diligência. Segundo a autora (apud McIntyre, 2007, p. 221):

It may be argued that such assessments may be a relevant factor in determining whether a State has acted with the requisite degree of diligence in discharging its customary law or treaty-based to prevent environment harm. A State fails to assess the impact of proposed 
activities on the territories of other States can hardly claim that it has taken all practicable measures with a view to preventing environmental damage.

A questão que se coloca é a de saber em que medida o princípio da precaução deve ser obrigatoriamente respeitado quando da realização de uma avaliação de impacto ambiental ou de risco à saúde; em outras palavras, qual o seu peso e alcance no momento de uma decisão definitiva. A dinâmica na aplicação do princípio da precaução pode ser resumida da seguinte maneira: o princípio da prevenção exige, na maioria das vezes, uma avaliação de impacto ambiental ou de risco à saúde, antecedendo mesmo ao princípio da precaução, que incidirá na medida em que essa avaliação não tenha chegado a uma decisão conclusiva por indisponibilidade de dados científicos suficientes.

Nesse sentido, discordamos de McIntyre que entende que o princípio da precaução incidiria antes mesmo da avaliação de impacto ambiental. Segundo o autor, o princípio da precaução é relevante para a decisão sobre a necessidade de se fazer a avaliação de impacto ambiental ou se o dano causado ou provavelmente a ser causado pela atividade em questão é significante no propósito da obrigação de prevenir o dano ambiental (McIntyre 2007, p. 221). Nesse sentido, Birnie e Boyle sublinham que o princípio da precaução pode ser aplicado para determinar quando a proposta de um projeto ou de uma atividade apresenta a probabilidade de ter impacto significante sobre o meio ambiente de Estados vizinhos, apontando, por conseguinte, para a necessidade de realizar uma análise de impacto ambiental (apud McIntyre, 2007, p. 239).

Qualquer que seja o momento de atuação do princípio da precaução, o fato é que organizações internacionais e órgãos de codificação parecen encarar os procedimentos de avaliação de impacto ambiental como essenciais para o cumprimento efetivo da obrigação de prevenir danos ambientais transfronteiriços e da respectiva obrigação de cooperar (McIntyre (2007, p. 239).

Conforme Kiss e Shelton (2007, p. 95), o princípio da precaução pode ser considerado a forma mais desenvolvida de prevenção, sendo que ambos inserem-se no contexto maior da obrigação do Estado de não causar danos a espaços fora de sua jurisdição (no-harm obligation); mandamento esse já consagrado em julgados internacionais ${ }^{4}$.

4 Nesse sentido, vide a declaração da CIJ no caso Gabcikovo-Nagymaros Project, retomando o enunciado na opinião consultiva Legality of the Threat or Use of Nuclear Weapons de 1996:

The environment is not an abstraction but represents the living space, the quality of life and 
Para Birnie e Boyle (apud McIntyre, 2007,pp. 198-199), a avaliação de impacto ambiental é um dos procedimentos imprescindíveis para evitar o dano. Nesse sentido, expressam os autores...

(I)t is beyond serious argument that states are required by international law to take adequate steps to control and regulates sources of serious global environmental pollution or transboundary harm within their territory or subject to their jurisdiction. This is a principle of harm prevention, not merely a basis for reparation after the event, although in its judicial application it has usually taken the latter form.

Em que pese a obrigação dos Estados de procederem a um estudo de impacto ambiental ou de risco à saúde, o direito internacional costumeiro em matéria de meio ambiente não prevê diligências específicas. Com efeito, procedimentos pré-estabelecidos somente existem dentro de regimes fechados, i.e. em instrumentos convencionais que apenas vinculam seus Estados partes, como, por exemplo, a Convenção da Comissão Econômica para a Europa das Nações Unidas (UNECE) Relativa à Avaliação do Impacto Ambiental num contexto Transfronteiriço, de $1991^{5}$, mais conhecida como Espoo Convention, que conta atualmente com 45 Estados Partes ${ }^{6}$.

No âmbito da União Européia, vamos encontrar menção vaga ao princípio da precaução na Diretiva 2011/92/EU (conhecida como 'Environmental Impact Assessment' - EIA Directive), a qual estabelece os princípios de avaliação que devem ser seguidos pelos Estados-Membros com vista a completar e coordenar os processos de aprovação de determinados projetos públicos ou privados que possam ter impacto importante no ambiente, facultando aos EstadosMembros o estabelecimento de regras mais restritivas em matéria de proteção ambiental (Considerando 3). Porém, a menção ao princípio da precaução se faz apenas em seus Considerandos, o de n. ${ }^{\circ} 2$, o qual informa que a política da União no domínio do meio ambiente baseiase no princípio da precaução, nos termos do artigo 191 do TFUE, sem prever, no decorrer do texto, sua forma concreta de aplicação ${ }^{7}$.

the very health of human beings, including generations unborn. The existence of the general obligation of State to ensure that activities within their jurisdiction and control respect the environment of other States or of areas beyond national control is now part of the corpus of international law relating to the environment (Gabcikovo-Nagymaros Project, Hungary v. Slovakia, judgment, 25 September 1997. ICJ Reports 1997, para. 140).

5 Em vigor desde 27 de junho 1997.

6 Instituições financeiras internacionais também costumam estabelecer procedimentos específicos para a avaliação de impacto ambiental, como é o caso da Diretiva do Banco Mundial de 1989 em sua primeira edição.

7 Essa mesma observação aplica-se à Diretiva 2001/42/CE do Parlamento Europeu e do 
A falta de parâmetros comuns na aplicação do princípio da precaução foi objeto de preocupação da Comissão Européia, de modo que publicou um comunicado estabelecendo diretrizes claras comuns aos Estados-Membros (Comunicado da Comissão, de 02 de fevereiro de 2000 (COM(2000)1 final - não publicado no Jornal Oficial $)^{8}$. De acordo com o referido comunicado, o recurso ao princípio da precaução deve ser guiado pelos seguintes parâmetros:

1. Uma avaliação científica tão completa quanto possível e a determinação, na medida do possível, do grau de incerteza científica;

2. Uma avaliação do risco e das potenciais conseqüências da não ação

3. A participação de todas as partes interessadas no estudo de medidas de precaução, logo que os resultados da avaliação científica e/ ou da avaliação estiverem disponíveis.

Ademais, o Comunicado determina que, sempre que o princípio da precaução for invocado, deverão ser aplicados os princípios gerais da gestão dos riscos, quais sejam:

1. A proporcionalidade entre as medidas tomadas e o nível de proteção procurado;

2. A não discriminação na aplicação das medidas;

3. A coerência das medidas com as já tomadas em situações similares ou que utilizem abordagens similares; da não ação;

4. O exame das vantagens e desvantagens resultantes da ação ou

5. O exame das medidas à luz da evolução científica.

Excetuado o sistema normativo da União Européia, verifica-se a ausência de um procedimento universal para a realização da avaliação de impacto ambiental. Nesse caso, Okowa sugere que alguns componentes devem constituir o núcleo duro de uma boa avaliação, referindo-se à Espoo Convention 1991 e aos Objetivos e Princípios sobre Estudo

Conselho (conhecida como Strategic Environmental Assessment - SEA Directive), aplicada para projetos públicos, que igualmente apenas faz menção ao princípio da precaução no seu Considerando 1.

8Disponívelem:http://europa.eu/legislation_summaries/environment/general_provisions/ 132042_pt.htm 
de Impacto Ambiental, adotado em 1987 pelo Programa das Nações Unidas para o Meio Ambiente, mais conhecido pela sigla em inglês UNEP (apud Mc Interyre, p. 238). Note-se, porém, que nenhum desses instrumentos contempla o princípio da precaução, como tampouco o faz o Draft Articles on Prevention of Transboundary Harm from Hazardous Activities, simples "guideline" que estabelece procedimentos a serem seguidos pelos Estados quando da realização de atividades potencialmente danosas a Estados vizinhos?.

A necessidade de utilizar o princípio da precaução como instrumento de análise nas avaliações de impacto ambiental foi trazida na demanda da Nova Zelândia de reexame pela CIJ do caso dos testes nucleares e, concomitantemente, de medida cautelar, visando a impedir que a França realizasse qualquer teste nuclear nos atóis de Mururoa e Fagataufa, no sul do Pacífico ${ }^{10}$. De acordo com a Nova Zelândia, a França somente poderia realizar tais testes, desta vez subterrâneos (e não mais aéreos como no caso julgado em 1974), se apresentasse indícios de que os mesmos não iriam contaminar, direta ou indiretamente, o meio ambiente marinho com a introdução de material radioativo, afetando direitos da Nova Zelândia e de outros Estados. De acordo com o pedido da Nova Zelândia, a França devia realizar sua avaliação de impacto ambiental utilizando-se, inclusive, do princípio da precaução, o qual, segundo a demandante, era amplamente aceito no direito internacional contemporâneo.

Como observa McIntyre (2007, p. 236), embora a maioria da Corte tenha rejeitado a demanda da Nova Zelândia, sem analisar o mérito da questão, os três votos dissidentes entenderam que a Nova Zelândia tinha sim um caso prima face. $\mathrm{O}$ autor sublinha particularmente o entendimento dos juízes Palmer e Weeramantry de que a necessidade de realizar um estudo de impacto ambiental é auxiliar ao princípio da precaução, e que tal necessidade poderia ser deduzida do artigo 12 da Convenção de Nouméa para a Proteção dos Recursos Naturais e do Meio Ambiente do Pacífico Sul de 1986, ${ }^{11}$ da qual Nova Zelândia e França são partes. O autor destaca, ainda, a posição do juiz Palmer de que tanto o princípio da precaução como o requerimento mais específico de avaliação de impacto ambiental poderiam, no momento,

9 Adotado em 2001 pela Comissão de Direito Internacional da ONU em segunda leitura, in Report of ILC on the Work of its Fifty-Third Session, April 23-June 1 and July 2-August 10, 2001. General Assembly official records (GAOR), Fifty-Sixth Session, Supp. No. 10 (A/56/10, p. 370). Yearbook of the International Law Commission, 2001, vol. II, Part Two.

10 Request for an Examination of the Situation in Accordance with paragraph 63 of the Court's Judgment of 20 December 1974 in the nuclear Tests (New Zealand v. France) Case Order 22IX 95, ICJ Rep. (1995). Disponível em: http://www.icj-cij.org/docket/files/97/7554.pdf 1126 ILM (1987) 38, em vigor desde 18/08/1990. 
serem considerados princípios de direito internacional costumeiro relacionados ao meio ambiente ${ }^{12}$.

O princípio da precaução foi trazido novamente à apreciação da CIJ, desta vez pela Hungria, no Caso Gabcikovo-Nagymaros, ${ }^{13}$ na tentativa de justificar seu estado de necessidade ambiental e eximir-se, assim, da obrigação imposta no tratado celebrado com a antiga Tchecoslováquia que previa diversas obras no Rio Danúbio com base em um projeto comum. Segundo a Hungria, havia um vínculo direto entre o princípio da precaução e a obrigação de cooperar e o dever de prevenir danos ambientais transfronteiriços, conforme se podia deduzir do artigo $3^{\circ} \mathrm{da}$ Espoo Convention 1991. Na realidade, o referido artigo trata, em diversos parágrafos, da obrigação de notificar o Estado afetado e da conseqüente constituição de uma comissão de inquérito quando as partes envolvidas não chegarem a um entendimento sobre a probabilidade da atividade em questão causar dano ambiental significante; em momento algum o artigo invocado pela Hungria se refere ao princípio da precaução.

Comovimos, embora o princípio da precaução possa ser subsidiário à obrigação de não causar dano, a CIJ, nos dois casos abordados acima, preferiu não dar-lhe maior importância. Poderíamos esperar outro comportamento da Corte? Acreditamos que não, porquanto, como já ressaltamos, de um lado os dispositivos invocados não faziam referência ao princípio e, de outro, os procedimentos de avaliação de impacto ambiental não o contemplam como elemento determinante.

Vamos observar a seguir que a dificuldade dos tribunais internacionais em dar eficácia ao princípio da precaução aumenta na medida em que se deparam com a incidência de princípios de víeis preponderantemente econômico, mais antigos e já consagrados do direito internacional.

\section{2) A concorrência do princípio da precaução com outros princípios do direito internacional}

A ponderação entre princípios e normas de direito é uma constante da atividade jurisdicional. Em matéria de proteção do meio ambiente ou da saúde a realidade não poderia ser diferente, mormente em se tratando de tema sensível à sociedade civil e ao mesmo tempo indesejado para os países que anseiam pelo desenvolvimento econômico.

12 Em realidade, o artigo 12 dispõe que "as partes devem adotar todas as medidas apropriadas para prevenirem, reduzirem ou controlar a poluição na área que podem resultar de resíduos de testes nucleares".

13 Gabcikovo-Nagymaros Project (Hungary v. Slovakia), judgment, 25 September 1997. ICJ Reports 1997. Disponível em: http://www.icj-cij.org/docket/files/92/7375.pdf 
Dentre os princípios que mais comumente se opõem ao princípio da precaução, e em geral aos princípios do direito internacional do meio ambiente, encontram-se o princípio da soberania exclusiva permanente do Estado sobre seus recursos naturais e o princípio do livre comércio. Neste capítulo, vamos observar qual a tendência de tribunais internacionais diante da concorrência entre tais princípios e o princípio da precaução.

2.1) O princípio da soberania exclusiva permanente sobre recursos naturais versus princípio da precaução

O Princípio da soberania exclusiva permanente do Estado sobre seus recursos naturais e seu corolário princípio do desenvolvimento econômico foram fundamentais no século XX, notadamente na década de 70, para legitimar medidas que visavam promover o desenvolvimento econômico dos Estados, especialmente dos países menos desenvolvidos.

O princípio teria alcançado status de norma consuetudinária, tendo sido consagrado em vários instrumentos internacionais, dentre os quais destacam-se: a Declaração sobre Soberania Permanente sobre Recursos Naturais (Resolução AGNU 1803/1962); a Carta de Direitos e Deveres Econômicos dos Estados (Resolução AGNU 3281/1974); ${ }^{14}$ a Convenção sobre Direitos Econômicos, Sociais e Culturais de 1966 e a Convenção sobre Direitos Civis e Políticos de 1966.

Com base nesse princípio, os Estados reivindicam sua competência exclusiva para dispor de seus recursos naturais da maneira que melhor convenha a seus interesses sociais, econômicos ou de segurança nacional, fazendo comumente "vistas grossas" sobre os efeitos danosos ao meio ambiente provocados por atividades econômicas realizadas em seu território ou sob sua jurisdição.

$\mathrm{Na}$ seqüência, faremos uma análise geral da jurisprudência internacional ao se posicionar entre a aplicação do princípio da soberania exclusiva do Estado sobre seu recursos naturais e o princípio da precaução.

No caso conhecido como "Pulp Mills"15, submetido à CIJ pela Argentina contra o Uruguai, e mais especificamente no pedido de medida

14 Essas duas Resoluções da ONU foram inclusive usadas por alguns países (e.g. Irã, Líbia, México e Venezuela) para legitimar a nacionalização de empresas privadas estrangeiras exploradoras de petróleo.

15 Pulp Mills on the River Uruguay (Argentina v. Uruguay), Provisional Measures, Order, 13 July 2006, ICJ Reports 2006. Disponível em: http://www.icj-cij.org/docket/files/135/11235. pdf 
provisória para suspender as obras de instalação de usinas de papel junto ao Rio Uruguay, a demandante refere-se apenas indiretamente ao princípio da precaução para justificar a necessidade da cautelar, a fim de evitar conseqüências danosas que por sua gravidade não poderiam mais ser reparadas com uma simples compensação ou outra forma de indenização material.

Por sua vez, a CIJ, passando ao largo do principio da precaução e do argumento argentino de que a continuidade das obras acabaria por dar ao Uruguai o pretexto do fato consumado (fait accompli), o que tornaria irreversível a atual localização das mesmas, não concedeu a provisória solicitada.

Segundo a Corte, a Argentina não tinha demonstrado que a construção das fábricas representava uma ameaça iminente de dano ao meio aquático do Rio Uruguay e que a construção em curso não poderia ser usada pelo Uruguai para criar uma situação de fato consumado, pois se eventualmente a Corte viesse a decidir pela ilegalidade da construção, as instalações poderiam ser destruídas ${ }^{16}$.

O Tribunal Internacional do Direito do Mar, mais conhecido pela sigla inglesa ITLOS, também foi chamado para dirimir um conflito no qual apenas indiretamente o princípio da precaução foi suscitado. Tratase do caso do "atum da nadadeira azul", ${ }^{17}$ em que o referido tribunal teve que decidir sobre o pedido de medidas provisórias feito por Nova Zelândia e Austrália a fim de impedir que o Japão continuasse seu programa experimental de pesca. Segundo as demandantes, o método utilizado pelas embarcações japonesas fazia com que o atum do sul de nadadeira azul acabasse por ser capturado acima da cota nacional estabelecida para os anos de 1987-1997, conforme acordo firmado entre as partes no conflito.

Embora o acordo não estivesse mais em vigor desde 1998, as demandantes alegaram que a necessidade de manter as respectivas cotas nacionais permanecia, tendo em vista a ameaça ao stock do atum do sul de nadadeira azul, que estaria reduzindo consideravelmente: o método de pesca japonês acabaria levando à extinção da espécie.

16 Em acórdão datado de 20/04/2010, a CIJ decide pela legalidade da instalação da usinas na área, muito embora tenha relembrado ao Uruguai de sua responsabilidade em caso de dano efetivo ao Rio Uruguay, retomando um ditame anterior de que os Estados tem a obrigação de adotar todas as medidas necessárias para que atividades em seu território não causem danos aos países vizinhos.

17 Southern Bluefin Tuna Cases (New Zealand v. Japan; Australia v. Japan), Requests for provisional Measures, Order, 27 August 1999. Disponível em: http://www.itlos.org/fileadmin/ itlos/documents/cases/case_no_3_4/Order.27.08.99.E.pdf 
Com base em alguns dispositivos genéricos da Convenção Internacional sobre o Direito do Mar de 1982, que tratam da preservação dos meios marinhos e de seus recursos naturais, o ITLOS ordenou, por maioria, que o Japão suspendesse imediatamente seu programa de pesca, mantendo sua cota anual de captura (6.065 toneladas), embora não houvesse nenhuma prova científica de que realmente o stock do atum do sul de nadadeira azul estivesse diminuindo. Segundo o Tribunal, a medida se justificaria com base na urgência de preservar os direitos das partes e evitar uma posterior deterioração da espécie ${ }^{18}$.

Afora o caso que acabamos de analisar, o qual aplicou o princípio da precaução em sua forma mais ampla, o fato é que dificilmente um tribunal irá impedir ou determinar a suspensão de uma atividade econômica "lucrativa" com base em um suposto dano, tendo prevalecido até o momento o princípio da soberania territorial do Estado. Como veremos a seguir, essa hipótese estaria ainda mais afastada quando está em jogo o princípio do livre comércio.

\section{2) O princípio do livre comércio versus princípio da precaução}

Dentre as regras preconizadas pelo Acordo Geral sobre Tarifas Aduaneiras e Comércio (mais conhecido pela sigla inglesa GATT), de 1994, que consubstanciam o princípio maior do livre comércio, está a obrigação dos Membros da Organização Mundial do Comércio (OMC) de não impor medidas quantitativas que tenham por efeito restringir o fluxo de comércio entre seus Membros (156 atualmente), também conhecidas como barreiras não-tarifárias, prevista essencialmente no artigo XI do GATT 1994.

Em geral, pode-se dizer que a ratio do sistema normativo da OMC é a de que o livre comércio promove o bem estar geral, eis que facilita a lei da vantagem econômica comparativa. Dessa forma, os governos devem limitar ao máximo sua atuação na economia, de modo a não interferir no fluxo de comércio e permitir que os agentes econômicos tornem-se eficientes e obtenham lucro.

Por outro lado, a fim de não subtrair a seus Membros toda e

18 Posteriormente essa medida provisória foi revogada pelo Tribunal Arbitral constituído de conformidade com o Anexo VII da Convenção sobre o Direito do Mar de 1982 para decidir sobre o mérito da controvérsia, o qual acatou a defesa japonesa de que não tinha jurisdição para julgar o caso (Southern Bluefin Tuna Case, Award on Jurisdiction and Admissibility, 04 August 2000, disponível em: https://icsid.worldbank.org/ICSID/FrontServlet?requestType=ICSIDPublicationsRH\&action Val=ViewAnnouncePDF\&Announcement Type=archive \&AnnounceNo=7_10.pdf) 
qualquer soberania sobre matérias mais sensíveis, o próprio GATT 1994 prevê, em seu artigo XX, situações que permitem a adoção de medidas que, embora restritivas de comércio, visem, dentre outros objetivos, a proteção da saúde ou da vida das pessoas, animais ou vegetais (alínea b), bem como a conservação dos recursos naturais não renováveis (alínea g).

Os casos expostos a seguir foram solucionados pelo mecanismo de solução de controvérsias da OMC e trataram da articulação entre a regra e as exceções acima mencionadas, trazendo à tona o princípio da precaução na tentativa de sustentar a legitimidade das medidas controversas. De forma sucinta, tentaremos demonstrar a tendência geral dos panels e do Órgão de Apelação ao se defrontarem com o referido princípio.

No caso 'CE-Carne com Hormônios',19 os EUA contestaram a normativa européia que proibia a importação de carne tratada com hormônios sintéticos que estimulam o crescimento do gado. Segundo os EUA, a medida violava dispositivos de diversos acordos da OMC, principalmente o artigo XI do GATT 1994, não estando amparada pela exceção do artigo XX, porquanto a CE não pôde demonstrar, mediante prova científica conclusiva, de que tal produto era prejudicial à saúde.

No que toca ao princípio da precaução, enquanto a França defendia que o referido princípio deveria ser aplicado ao caso, tendo este alcançado status de "norma consuetudinária geral do direito internacional", os EUA alegavam que o princípio da precaução nada mais era do que um simples enfoque.

Ainda que a França tivesse argumentado perante os órgãos judicantes da OMC de que não era necessário que todos os cientistas do mundo estivessem de acordo sobre a possibilidade e a magnitude dos riscos e que nem todos os Membros da OMC entendessem e avaliassem o risco da mesma forma, não obteve sucesso.

Com efeito, enquanto o Panel aceita o princípio, mas refuta a defesa da França por entender que o princípio da precaução não podia prevalecer sobre os textos dos Acordos da OMC, restringindo sua aplicação às medidas provisórias, o Órgão de Apelação, em grau de recurso, sequer reconheceu a autoridade normativa do princípio.

19 European Communities - Measures concerning Meat and meat Products (EC - Hormones), WTO- Panel Report WT/DS26/R/USA adotado em 18/08/1997 e Appellate Body Report WT/ DS48/AB/R, adotado em 16/01/ 1998. Disponível em: http://www.wto.org/english/tratop_e/ dispu_e/cases_e/ds26_e.htm 
Nesse sentido, o referido Órgão expressa que não há consenso entre os acadêmicos, profissionais do direito, órgãos normativos e juízes sobre o status jurídico do princípio, não estando claro que o mesmo tenha sido aceito amplamente pelos Membros da OMC. Em qualquer caso, o Órgão de Apelação entendeu que ainda que houvesse tal reconhecimento, o princípio da precaução não poderia servir para justificar medidas sanitárias e fitossanitárias incompatíveis com as obrigações decorrentes dos acordos da $\mathrm{OMC}^{20}$.

Esse posicionamento foi mantido em caso posterior, conhecido como "EC-Biotech", ${ }^{21}$ no qual a UE foi questionada em virtude de uma sua normativa que permitia aos Estados-Membros, a título de "salvaguarda", a adoção unilateral de medidas restritivas de comércio sobre produtos geneticamente modificado, ainda que tivesse havido aprovação prévia da Comissão Européia. Para tanto, bastava que o Estado interessado tivesse razões para acreditar que o produto acarretava risco à saúde e ao meio ambiente face à superveniência de conhecimento científico novo ou complementar que pudesse alterar a avaliação de risco previamente feita.

O Panel decidiu a favor das reclamantes (Argentina, Canadá e EUA), relembrando que não havia até o momento nenhuma decisão mandatória de uma corte ou tribunal internacional que tivesse reconhecido o princípio da precaução como princípio geral ou costumeiro de direito internacional. Ademais, estatuiu que a normativa européia não encontrava respaldo nas exceções do Artigo XX do GATT 1994, eis que a "salvaguarda" permitida aos Estados-Membros não condicionava a que estes dispusessem de provas científicas suficientes para inferir que os produtos em causa provocariam dano à saúde ou ao meio ambiente ${ }^{22}$.

Em que pese às considerações feitas pelos tribunais internacionais favoráveis ao meio ambiente, o fato é que tem prevalecido na jurisprudência internacional princípios que, em última análise, visam a promover o desenvolvimento econômico dos Estados, sem uma preocupação maior com os efeitos sócio-ambientais negativos que

20 Em acordo de 13/05/2009 celebrado entre as partes e comunicado ao Órgão de Solução de Controvérsias da OMC em 25/09/2009, os EUA aceitaram que a UE continuasse proibindo a entrada de carne tratada com certos hormônios promovedores de crescimento, mas passa a aplicar tarifas mais elevadas sobre a importação de certos produtos procedentes da UE.

21 European Communities - Measures Affecting the Approval and Marketing of Biotech Product, WTO- Panel Report WT/DS291/R/, adotado em 29/09/2006. Disponível em: http:// www.wto.org/english/tratop_e/dispu_e/cases_e/ds291_e.htm

22 Em acordos celebrados com os reclamantes e comunicados ao Órgão de Solução de Controvésias em 14/01/2008, a UE foi obrigada a lhes conceder compensações a fim de evitar contramedidas comerciais. 
as medidas adotadas a esse título possam vir a ter. Segundo André Nollkaemper (apud Ebbesson, 2007, p. 21), o desejável seria que o direito internacional estabelecesse, de forma concreta, um conjunto de normas que deveriam determinar como um Estado faria sua escolha entre meioambiente, desenvolvimento social e outros valores não econômicos

No âmbito regional, a situação não é muito diferente eis que a problemática que domina o debate também se encontra presente nas áreas de integração econômica. Nesse sentido, passaremos à análise da jurisprudência da União Européia e do Mercosul sobre a aplicação do princípio da precaução nos seus respectivos comércios intra-bloco.

\section{Parte II: A Jurisprudência da União Européia e do Mercosul acerca do Princípio da Precaução}

A proteção do meio ambiente encontra-se dentre os objetivos tanto da União Européia (UE) como do Mercosul, embora exista um descompasso entre as duas áreas de integração quanto à adoção de medidas efetivas com essa finalidade.

Com efeito, na UE a proteção do meio ambiente não constitui apenas uma idéia abstrata, mas foi merecedora de uma política comum, bem como de normativa harmonizadora e mesmo unificadora da legislação de seus Estados-Membros.

No Mercosul, o tema foi acolhido de forma geral no segundo considerando do Tratado de Assunção de 1991, o qual expressa que o objetivo da integração entre seus Estados Partes deve ser alcançado mediante "o aproveitamento mais eficaz dos recursos disponíveis e a preservação do meio ambiente, entre outros meios".

Nesta $2^{\text {a }}$ parte do trabalho, iremos observar como os órgãos judicantes dessas duas áreas de integração tem interpretado e aplicado o princípio da precaução nas relações que se estabelecem no interior de seus respectivos mercados.

\section{1) A posição ambígua do Tribunal de Justiça da União Européia (TJUE) acerca do princípio da precaução}

O Princípio da precaução é um dos instrumentos da política ambiental comum da União Européia. Com efeito, o artigo 191.2 do TFUE determina que a política da UE em matéria de meio ambiente deve basear-se em diversos princípios, tais como: o princípio da precaução e 
da ação preventiva, da correção, prioritariamente na fonte, dos danos causados ao meio ambiente, e do poluidor-pagador.

Curioso notar, por outro lado, que o artigo 114.3 do TFUE, ao tratar das propostas normativas visando à aproximação das legislações nacionais em matéria de meio ambiente, dentre outras, determina que tais propostas devem buscar um nível de proteção elevado, tendo em conta nomeadamente nova evolução baseada em dados científicos.

Em que medida os dispositivos acima são complementares ou contraditórios não nos parece claro, mesmo porque a própria jurisprudência do TJUE parece oscilar entre a aplicação do princípio da precaução em sua forma mais "pura" e a necessidade de dados científicos concretos que justifiquem a adoção de medidas restritivas de comércio. Nicolas de Sadeleer opta pela segunda tendência ao referirse à jurisprudência do TJUE. O autor afirma que, embora os EstadosMembros da UE possam adotar medidas restritivas de comércio, a despeito de norma comunitária harmonizadora, quando circunstâncias demográficas, geográficas ou epidemológicas justifiquem tais medidas excepcionais, que visam, em geral, a proteção da saúde e do meio ambiente, invocando inclusive o princípio da precaução para se prevenir contra a ocorrência de riscos incertos, tais medidas restritivas de comércio somente são legítimas se tiverem sido adotadas com base em informações científicas (apud Ebbensson, 2009, p. 34).

A nosso ver, essa assertiva deve ser mitigada, eis que não nos parece ser sempre o caso, conforme se pode inferir dos acórdãos proferidos nos três casos que trazemos à análise neste trabalho: Ação de incumprimento (sic) C-333/08; Decisão prejudicial C-343/09 e Decisão prejudicial C-15/10.

Na Ação de incumprimento (sic) C-333/08, a Comissão Européia acusa a República Francesa (Acórdão de 28/01/2010) de impor uma restrição quantitativa à importação, contrária à livre de circulação de mercadorias, ao exigir autorização prévia para os aditivos tecnológicos (AT) ou gêneros alimentícios em cuja preparação fossem utilizados aditivos tecnológicos procedentes dos demais Estados-Membros, ainda que nesses Estados tenham sido legalmente fabricados e/ou comercializados $^{23}$. De acordo com a lei francesa, somente os produtos

23 Nos termos da Diretiva 89/107/CEE, os AT são substâncias utilizadas no processo de elaboração ou fabrico de gêneros alimentícios que visam a obtenção de um determinado efeito técnico durante esse processo, mas que não são consumidos como ingrediente alimentar em si, embora o produto final de consumo possa apresentar resíduos técnicos inevitáveis da substância em causa. Esses aditivos podem ser utilizados na medida em que não apresentem qualquer risco sanitário ou não produzam efeitos tecnológicos sobre o produto acabado (artigo $1^{\circ}$, 
dessa categoria inscritos em uma lista francesa "positiva” é que poderiam ser introduzidos automaticamente no território francês.

Vale lembrar que, se por um lado os AT não foram objeto de harmonização horizontal na UE, de modo que os Estados-Membros podem regulamentar a sua utilização, desde que respeitem as regras do Tratado $\mathrm{CE}^{24}$, por outro lado o comércio dos gêneros alimentícios em geral encontra-se disciplinado no Regulamento (CE) n. ${ }^{\circ} 178 / 2002$, o qual estabelece, inter alia, os princípios e normas gerais da legislação alimentar. Nesse sentido, em suas considerações dispõe que "a livre circulação de gêneros alimentícios e de alimentos para animais na Comunidade só poder ser alcançada se os requisitos de segurança dos gêneros alimentícios e dos alimentos para animais não diferirem de forma significativa entre os Estados-Membros" (Terceiro considerando).

Para evitar entraves desnecessários ao comércio, o regulamento em causa determina que os Estados-Membros, ao visarem um nível elevado de proteção da vida e da saúde humanas, deverão fazer sua avaliação de riscos baseada em provas científicas disponíveis, de forma independente, objetiva e transparente (artigo 6 parágrafos 1 e 2). Todavia, referindo-se ao princípio da precaução, o parágrafo 1 do artigo 7 determina que se uma possibilidade de risco for identificada, mas persistirem incertezas a nível científico, o Estado-Membro poderá adotar medidas provisórias de gestão dos riscos, ainda que restritivas do comércio, enquanto se aguardam outras informações científicas que permitam uma avaliação mais exaustiva dos riscos. O parágrafo 2 do mesmo dispositivo, por sua vez, condiciona a legalidade da medida a que esta seja proporcional, i.e, não seja mais restritiva do que o necessário para assegurar o elevado nível de proteção da saúde. Obviamente, essa faculdade do EstadoMembro somente existe na medida em que não há norma comunitária específica sobre o gênero alimentício em causa.

Ocorre que a legislação francesa, Decreto de 1912, proibia a aquisição para venda ou a colocação à venda de produtos ou gêneros alimentícios destinados à alimentação humana que contivessem aditivos químicos que não tivessem sido expressamente autorizados pelas autoridades francesas competentes na matéria (artigo 1). Ademais, o Decreto proibia a utilização na preparação desses produtos e gêneros alimentícios de produtos químicos que não tivessem sido previamente autorizados (artigo 2).

n. ${ }^{\circ}$, alínea a). Por outro lado, nos termos da Diretiva 2000/13, os aditivos utilizados como AT não são considerados ingredientes (art. $6^{\circ}$, n. $^{\circ} 4$, alínea c, ii) e, por conseguinte, não necessitam constar nos rótulos, apresentação e publicidade dos gêneros alimentícios.

24 Substituído, em 2010, pelo Tratado de Funcionamento da União Européia (TFUE). 
Em geral, a autorização para comercializar AT estava condicionada ao respeito de critérios de pureza e outras características definidas na regulamentação francesa. Da mesma forma, a comercialização de gêneros alimentícios acabados somente seria autorizada se os mesmos não contivessem AT proibidos ou obedecessem um teor residual máximo de AT autorizados.

O Decreto n. ${ }^{\circ}$ 2001-725, em seu artigo 2, lista os AT cuja utilização é autorizada, as condições de sua utilização e os limites máximos de resíduos admissíveis, permitindo, no artigo 3, eventual alteração/ complemento dessa lista mediante requerimento de qualquer pessoa interessada. Assim sendo, somente os gêneros alimentícios destinados à alimentação humana que possuam AT listados é que podem ser adquiridos, vendidos ou distribuídos a título gratuito no mercado francês.

No que importa à aplicação do princípio da precaução no caso em tela, ressaltamos as considerações do TJUE sobre a justificativa francesa de proteção da saúde, expressas no Acórdão de 28/01/2010²5.

Primeiramente, o TJUE partiu da premissa de que o regime de autorização prévia do Decreto 1912 constituía uma medida de efeito equivalente a uma restrição quantitativa na acepção do artigo 28 do TCE (atual artigo 34 do TFUE), eis que tornava mais onerosa e difícil, ou em certos casos, impossível a comercialização de AT e gêneros alimentícios em cuja preparação foram utilizados AT legalmente fabricados e/ou comercializados noutros Estados-Membros (Parágrafos 75 e 76). A partir daí, tornava-se necessário determinar se tal medida restritiva de comércio encontrava respaldo no artigo 30 do TCE (atual artigo 36 do TFUE), nomeadamente no objetivo de proteção da saúde pública.

Basicamente, a análise do TJUE concentrou-se na modalidade de aplicação do princípio da proporcionalidade, referindo-se concomitantemente ao princípio da precaução como elemento subsidiário. Com efeito, remitindo-se a julgados anteriores, nomeadamente dos casos C-192/01 e C-24/00, o TJUE determinou que os Estados-Membros, ao exercerem o seu poder de apreciação relativo à proteção da saúde pública, deviam respeitar o princípio da proporcionalidade, o que implica impor limites a sua escolha: os meios devem ser efetivamente necessários para assegurar a proteção da saúde pública e proporcionais aos objetivos perseguidos, os quais não poderiam ser alcançados por medidas menos restritivas de comércio no

25 Disponível em http://curia.europa.eu/juris/document/document.jsf?text=\&doci$\mathrm{d}=74482$ \&pageIndex $=0$ \&doclang $=$ PT\&mode $=1$ st \&dir $=\&$ occ $=$ first\&part $=1 \&$ cid $=717257$ 
mercado interno europeu (Parágrafo 90).

Em primeira análise, o TJUE estabeleceu que as decisões dos Estados-Membros que restringem o comércio estão condicionadas a que o alegado risco real à saúde pública esteja suficientemente demonstrado com bases em dados científicos mais recentes, disponíveis na data de adoção dessa decisão. Dessa forma, a avaliação do risco tem por objetivo apreciar o grau de probabilidade dos efeitos nefastos da utilização do produto à saúde humana e a gravidade desses potenciais efeitos (Parágrafo 89).

Por outro lado, o TJUE reconheceu que a apreciação a que o Estado-Membro tem de proceder pode revelar que existe um grau de incerteza científica e prática a esse respeito. Tal incerteza, inseparável do conceito de precaução, influencia o alcance do poder de apreciação do Estado-Membro, repercutindo-se, assim, nas modalidades de aplicação do princípio da proporcionalidade. Nessas circunstâncias, o TJUE admite que um Estado-Membro pode, ao abrigo do princípio da precaução, adotar medidas de proteção sem ter de esperar que a realidade e a gravidade de tais riscos estejam plenamente demonstradas (Parágrafo 91).

Paradoxalmente, na seqüência de seu entendimento, o TJUE prescreve que a aplicação correta do princípio da precaução pressupõe, em primeiro lugar, a identificação das conseqüências negativas potenciais à saúde da utilização da substância em causa e, em segundo lugar, da avaliação completa dos riscos para a saúde fundada sobre dados científicos disponíveis e mais fiáveis, bem como dos resultados mais recentes de pesquisas internacionais (Parágrafo 92).

Nesse aspecto, o TJUE acompanhou a alegação da Comissão de que o regime de autorização prévia assentava-se em presunção generalizada do risco para a saúde e não em justificação precisa de natureza científica. O TJUE não encontrou suporte nos elementos apresentados pela França para explicar a razão pela qual a comercialização de qualquer gênero alimentício em cuja preparação foram utilizados AT legalmente fabricadas e/ou comercializadas em outros Estados-Membros devesse depender de inclusão dos AT em causa em uma lista positiva estabelecida pela regulamentação francesa, inclusão esta que dependia da conformidade de vários critérios especificados nessa regulamentação. Segundo o TJUE, ao existirem riscos associados a certas categorias de AT, a regulamentação nacional deve concentrar-se nessas categorias e ser claramente justificada a respeito delas, não devendo visar todos os AT ou todos os gêneros alimentícios em cuja preparação foram utilizados os 
AT não pertencentes a essas categorias perigosas e suspeitas (Parágrafo 97).

Logo, o TJUE entendeu ser desproporcional a decisão interna que, exceto em caso de autorização prévia, proíbe de forma sistemática a comercialização de qualquer AT ou gênero alimentício em cuja preparação foram utilizados AT legalmente fabricados e/ou comercializados noutros Estados-Membros, sem distinguir em função dos diferentes AT ou segundo o nível de risco que a sua utilização pode representar para a saúde (Parágrafo 100) ${ }^{26}$.

Mas se no caso que acabamos de analisar o TJUE parece ter feito uma interpretação cautelosa e restritiva do princípio da precaução, para, ao final, condenar a regulamentação francesa por ser contrária ao livre comércio de bens no mercado europeu, não beneficiando da exceção da proteção da saúde pública, já não podemos inferir o mesmo de alguns de seus julgados posteriores.

Com efeito, quando da análise sobre a validade de normas comunitárias que harmonizam e/ou uniformizam a legislação dos Estados-Membros em matéria de proteção da saúde e do meio ambiente, vislumbramos maior acolhida e importância dada ao princípio da precaução pelo TJUE, que passa a ter papel mais decisivo e não mais de simples coadjuvante.

Na Decisão prejudicial C-343/09, submetida pela High Court of Justice (England \& Wales), Queen's Bench Division (Administrative Court), do Reino Unido, o TJUE foi chamada a decidir sobre a validade da regulamentação comunitária ${ }^{27}$ que, por um lado, estabelecia um teor máximo do aditivo metálico tricarbonilo metilciclopentadienil de manganês (MMT) nos carburantes e, por outro, exigia a informação aos consumidores da presença da referida substância.

Segundo a autora no processo interno (Afton Chemical Limited contra Secretary of State for Transport), a normativa européia violava diversos princípios da ordem jurídica comunitária, dentre os quais o da precaução e da proporcionalidade.

26 Note-se que, embora em Decreto posterior - Decreto de 2001 - a França tivesse assegurado a livre circulação de AT e gêneros alimentícios procedentes dos demais EstadosMembros da UE e do Espaço Econômico Europeu (EEE), mediante um sistema de reconhecimento mútuo de certificação, o TJUE o desconsiderou tendo em vista que o mesmo ainda não havia entrado em vigor na França até o prazo fixado durante a fase pré-contenciosa no parecer fundamentado da Comissão, que se deu em 04/09/2006. O TJUE entendeu que no momento do contencioso havia na França uma situação de insegurança jurídica para os operadores econômicos.

27 Diretiva 2009/30/CE e Diretiva 98/70/CE. 
O TJUE, em Acórdão de 08/07/2010, ${ }^{28}$ embora se apóie recorrentemente no acórdão que acabamos de analisar (C-333/08), acaba por justificar a legalidade da normativa comunitária.

Nesse sentido, retoma o entendimento de que quando se verifica a impossibilidade de determinar com certidão a existência ou o porte do risco alegado em razão da natureza insuficiente, não concludente ou imprecisa dos estudos realizados, mais do que a probabilidade de um dano real para a saúde pública, persiste na hipótese onde o risco se realizaria o princípio da precaução, o qual justificaria a adoção de medidas restritivas, sob reserva de que tais medidas sejam nãodiscriminatórias e objetivas (Parágrafos 61 C-343/09 e 92 C- 333/08). Por conseguinte, o TJUE estabelece que nessas condições o legislador da União pode, em virtude do princípio da precaução, adotar medidas de proteção sem ter que esperar que a realidade ou a gravidade de tais riscos seja demonstrada (Parágrafos 62 C-343/09 e 91 C-333/08).

Ao responder a alegação da Afton de que o nível máximo de MMT nos carburantes foi determinado sem nenhum embasamento científico e de que a Comissão não teria levado em conta os inconvenientes desse teor reduzido para os veículos antigos, o que, levaria, de fato, a uma interdição do MMT, o TJUE respondeu que quando incertezas existem quanto aos danos suscetíveis de serem causados pelo MMT, não pode haver informações mais precisas que permitam definir qual o nível de teor limite do MMT nos carburantes que seriam capazes de prevenir adequadamente esses mesmos danos (Parágrafo 66). Por conseguinte, tendo em vistas as incertezas sobre os danos causados pela utilização do MMT, bem como sobre os riscos gerados por sua utilização, a fixação de teor limites em MMT nos carburantes não parece desproporcional em relação aos interesses econômicos do produtor de MMT, com vistas a garantir um nível elevado de proteção da saúde e do meio ambiente.

O TJUE conclui que a regulamentação comunitária em análise não violava nem o princípio da precaução e nem o da proporcionalidade (Parágrafo 69); tendência essa que será mantida em caso submetido posteriormente ao TJUE, como veremos.

Na Decisão prejudicial C -15/10, submetida pela High Court of Justice (England \& Wales), Queen's Bench Division (Administrative Court), do Reino Unido, o TJUE, em Acórdão de 21/07/2011, ${ }^{29}$

28 Disponível em http://curia.europa.eu/juris/document/document.jsf?text=\&doci$\mathrm{d}=79066$ \& pageIndex $=0 \&$ doclang $=\mathrm{PT} \&$ mode $=1$ st $\& \mathrm{dir}=\&$ occ $=$ first \&part $=1 \& \mathrm{cid}=717528$

29 Disponível em http://curia.europa.eu/juris/document/document.jsf?text=\&doci$\mathrm{d}=107921$ \&pageIndex $=0 \&$ doclang $=$ pt $\&$ mode $=$ lst \&dir $=\&$ occ $=$ first $\&$ part $=1 \&$ cid $=717675$ 
determinou como válida a normativa comunitária ${ }^{30}$ que classificara na categoria 2 as substâncias à base de borato como tóxicas para a reprodução, e não na categoria 3 , menos grave, como desejava a autora no processo interno (empresa Etimine SA, contra Secretary of State for Work and Pensions, do Reino Unido). Segundo a autora, a medida classificatória deveria ser diferida face a estudos que ainda estavam em curso e que poderiam por em causa a referida classificação.

O TJUE justificou a validade da normativa no princípio da precaução, que segundo o tribunal "é aplicado no âmbito sensível da proteção da saúde humana e do ambiente, tal como resulta de uma leitura conjugada dos Artigos 95 n. ${ }^{\circ} 3, \mathrm{CE}$ (atual Artigo 114 do TFUE) e 174 n.os1 e 2, CE (atual Artigo 191 do TFUE)" (Parágrafo 129). Esse princípio, em realidade, teria sido utilizado pelo TJUE como elemento essencial para determinar a adequação da normativa ao princípio da proporcionalidade, um dos princípios gerais do direito comunitário.

Ao final do estudo desses casos podemos concluir que a jurisprudência do TJUE parece-nos um pouco tendenciosa conforme se trate de medidas restritivas de comércio adotadas, de um lado, pelos Estados-Membros e, de outro, pela própria normativa comunitária. No primeiro caso, o princípio da precaução encontrar-se-ía condicionado ao respeito de certas condições e atuaria de forma subsidiária ao princípio da proporcionalidade, ao passo que no segundo o princípio seria aplicado de forma autônoma e mais flexível, aproximando-o da intenção original de seu criador.

\section{2) As posições divergentes dos tribunais do Mercosul acerca do princípio da precaução}

Diferentemente da jurisprudência da UE em matéria de meio ambiente e de proteção da saúde, no Mercosul ainda não podemos dizer que existe uma tendência consolidada acerca do princípio da precaução.

Isso porque, até o momento, somente um caso referindo-se à proteção do meio ambiente/saúde foi levado ao seu mecanismo de solução de controvérsias, o que nos parece ser insuficiente para consagrar

30 Directiva 2008/58/CE da Comissão, de 21 de Agosto de 2008, que altera, tendo em vista a trigésima adaptação ao progresso técnico, a Directiva 67/548/CEE do Conselho relativa à aproximação das disposições legislativas, regulamentares e administrativas respeitantes à classificação, embalagem e rotulagem das substâncias perigosas, bem como por outro, do Regulamento (CE) n. ${ }^{\circ}$ 790/2009 da Comissão, de 10 de Agosto de 2009, que altera, para efeitos da sua adaptação ao progresso técnico e científico, o Regulamento (CE) n. ${ }^{\circ}$ 1272/2008 do Parlamento Europeu e do Conselho relativo à classificação, rotulagem e embalagem das substâncias e misturas. 
uma jurisprudência. Ademais, o referido caso originou entendimentos opostos do Tribunal Arbitral Ad Hoc (TAH) e do Tribunal Permanente de Revisão (TPR), gerando incertezas sobre seu real alcance.

O caso em tela - "Argentina: proibição de importar pneus remoldados" - foi proposto pelo Uruguai contra a Argentina, com fundamento de que a Lei 25.626 de 09/08/2002, que proibia a importação de pneumáticos reformados, restringia o comércio na região ao criar uma barreira ao livre fluxo de mercadorias, sendo, portanto, contrária ao Artigo $1^{\circ}$ do Tratado de Assunção de 1991 e outras normativas do Mercosul.

Enquanto a Argentina apóia sua defesa essencialmente na proteção do meio ambiente e da saúde, o Uruguai prefere não atribuir maior importância ao tema, preferindo utilizar argumentos mais técnicos, conforme observa o TAH em seu laudo (Parágrafo 81 ) $^{31}$.

Com efeito, a Argentina utiliza-se da exceção do Artigo 50 do Tratado de Montevidéu, em remissão do artigo $2^{\circ}$, letra b do Anexo I do Tratado de Assunção de 1991, para sustentar que a lei contestada pelo Uruguai era uma medida de caráter preventivo destinada a evitar o dano potencial dos pneumáticos remodelados ao meio ambiente, à saúde das pessoas, animais e vegetais, comprometendo o desenvolvimento de gerações presentes e futuras (Parágrafo 27). Por sua vez, conforme observou o TAH, a posição do Uruguai durante o curso do processo foi a de não atribuir maior importância ao tema ambiental, apoiando-se em fundamentações mais técnicas (Parágrafo 81).

Acolhendo o entendimento da Argentina, o TAH refere-se inicialmente ao Princípio 15 da Declaração do Rio de 1992, a qual, como visto, consagra o princípio da precaução, reafirmando que "quando houver perigo de dano grave ou irreversível ao meio ambiente, a falta de certeza científica não deve servir como motivo para não adotar medidas julgadas necessárias" (Parágrafo 61).

Ainda nesse sentido, o TAH expressou que "em consonância com o princípio da integridade territorial, o princípio da precaução determina que o poder público utilize critérios científicos objetivos que conduzam ao equilíbrio entre a adoção de decisões para resultados a longo prazo e a satisfação de necessidades de curto prazo" (Parágrafo 69).

No entender do tribunal, a "incerteza científica", derivada do

31 Laudo N.o 11 do Tribunal Ad Hoc do Mercosul, de 25/10/2005 "Proibição de importar pneus remoldados" (revogado pelo Laudo do TPR), disponível em http://www.mercosur.int 
atraso e precariedade do conhecimento científico, deve ser incorporada como componente das políticas ambientais (Parágrafo 69). Acrescenta, ainda, que essa incerteza não pode ser um obstáculo para adoção de medidas de precaução e defesa e que dever-se-ia inverter o ônus da prova àquele que pretende implantar uma atividade considerada nociva ou potencialmente perigosa ao meio ambiente, demonstrando que tal atividade é segura e não constitui um perigo ecológico (Parágrafo 70).

Concluiu o TAH que os pneumáticos reformados, por terem vida útil menor do que a dos pneus novos, aumentando de forma acelerada o passivo ambiental, causam danos ao meio ambiente, eis que liberam substâncias danosas à natureza, bem como à saúde, porquanto se transformam em autênticos criadores de insetos transmissores de doenças (Parágrafo 80). Dessa forma, a medida argentina, embora restritiva do comércio intra-bloco, estava justificada e amparada pela normativa do Mercosul.

Contudo, a consagração do princípio da precaução pelo Tribunal Arbitral Ad Hoc do Mercosul não se manteve por muito tempo. Com efeito, inconformado com a vitória da Argentina em primeira instância, o Uruguai consegue junto ao Tribunal Permanente de Revisão do Mercosul (TPR), em grau de recurso, reverter a seu favor o julgado, conforme se depreende do laudo proferido em 20/12/2005 $5^{32}$.

No tocante especificamente à exceção ambiental, o TPR descarta o entendimento do TAH de que era necessário fazer uma ponderação entre os princípios do livre comércio e da proteção do meio ambiente, eis que para o TPR deve prevalecer, em qualquer caso, o direito da integração, sob pena de se cometer o pecado original de desconhecer sua autonomia em relação ao direito nacional e ao direito internacional, referindo-se a Alejandro Perotti (Parágrafo 9).

Concretamente, o TPR repreende ao laudo do TAH de ter cometido um erro de direito ao não detalhar e, por conseguinte, não avaliar os critérios que devem ser respeitados para que um Estado possa justificar uma medida restritiva de comércio nas exceções do Artigo 50 do Tratado de Montevidéu, notadamente na exceção ambiental, ainda que reconheça que tais critérios não estão previstos na normativa do Mercosul (Parágrafo 14).

32 Laudo n. ${ }^{\circ}$ 1/2005 do Tribunal Permanente de Revisão, de 20/12/2005 "Laudo do Tribunal Permanente de Revisão constituído para resolver o recurso apresentado pela República Oriental do Uruguai contra o laudo do Tribunal Arbitral Ad Hoc de 25 de outubro de 2005 na controvérsia 'proibição de importar pneus remoldados procedentes do Uruguai'”, disponível em http://www.mercosur.int 
Tomando como base acórdãos proferidos pelo TJUE, o TPR analisa se a medida argentina era não-discriminatória, justificada por razões ambientais, ou seja, necessária para alcançar o objetivo proposto e, por último, proporcional, i. e, não era mais rigorosa do que o necessário para alcançar o objetivo almejado: critérios esses aplicados cumulativamente e que, segundo o TPR, não foram preenchidos pela medida argentina (Parágrafos 15, 16 e 17).

Nesse ponto, importa-nos explicitar o entendimento do TPR sobre o princípio da precaução quando da análise do critério da proporcionalidade, ao manifestar-se que "o dano alegado não era nem grave nem irreversível, pressupostos que devem estar presentes para a aplicação do princípio".

Ainda sobre o princípio da precaução, discorda o TPR do laudo arbitral que invertera o ônus da prova ao Uruguai sob o argumento da incerteza científica (Parágrafo 19). Em sentido oposto, o TPR entendeu que cabe àquele quem excepciona a regra demonstrar o dano. Por outro lado, sublinhou que no caso em concreto não havia nenhuma incerteza científica quanto aos riscos associados aos pneus jogados no lixo e ainda que houvesse essa incerteza, esta, por si só, não poderia justificar a adoção de "qualquer" medida, como era o caso da restrição de importar pneus reformados (Parágrafo 20).

A bem da verdade, no caso que acabamos de ver, não havia lugar para a aplicação do princípio da precaução, porquanto, como bem sublinhou o TPR, em momento algum se discutiu sobre a necessidade da medida argentina para proteger o meio ambiente/saúde de um dano potencial: a questão era a de saber se a medida restritiva adotada pela Argentina respeitava as condições necessárias para excepcionar a regra mais geral da livre circulação de mercadorias no Mercosul.

Resta, portanto, ainda em aberto o alcance que o princípio da precaução possui no âmbito do Mercosul, mesmo porque o bloco ainda carece de uma política comum em matéria de meio ambiente e mais ainda de medidas concretas de implementação: somente a partir daí e de uma jurisprudência constante de seus tribunais é que poderíamos arriscar um posicionamento mais firme.

\section{Conclusão}

Não resta dúvida de que o princípio da precaução constitui um dos princípios do direito internacional do meio ambiente, atuando conjuntamente com outros princípios desse sub-ramo do direito 
internacional. Contudo, a autoridade do princípio enquanto norma costumeira internacional ainda é um anseio da sociedade civil.

Aliado a sua falta de previsão nos procedimentos de avaliação de impacto ambiental, o princípio da precaução ainda sofre pela falta de conteúdo e critérios claros para sua aplicação, carecendo de formulação legal precisa. Nesse sentido, Kiss e Shelton (2007, p. 89) expressam que a grande maioria dos princípios do direito internacional do meio ambiente tem sido chamados de "normas sem conteúdo determinado", possuidores de uma abstração tão grande a ponto de tornar impossível deduzir deles obrigações precisas com algum grau de certeza.

Da mesma forma, manifesta-se D. Bodansky (apud McIntyre 2007, p. 192-193) ao alegar que se fossem levados em conta critérios ortodoxos para a análise do direito internacional costumeiro, chegaríamos à conclusão de que poucos princípios do direito internacional do meio ambiente se qualificariam como costumeiro. $\mathrm{O}$ autor esclarece que grande parte das supostas normas costumeiras do direito internacional do meio ambiente informadas pelos doutrinadores em geral, dentre as quais o princípio da precaução, não está baseada em pesquisas sobre as práticas dos Estados, mas sim em referência em textos produzidos por atores não estatais, tais como tribunais internacionais judiciais ou arbitrais, organizações internacionais e organizações não governamentais e juristas. Por conseguinte, o autor caracteriza esses textos mais como "declaratórios" do que normas costumeiras, reconhecendo que, embora tenham uma utilidade limitada na resolução de conflitos pelos tribunais judiciais ou arbitrais, podem desenvolver um importante papel em termos de aplicação voluntária pelos Estados e nas negociações internacionais.

Com efeito, retornando à redação do Princípio 15 da Declaração do Rio, observamos que há termos abertos, que condicionam a aplicação do princípio da precaução a que o dano seja sério ou irreversível e ao custo-eficácia das medidas preventivas: difícil extrair daí uma obrigação precisa para os Estados.

Assim sendo, os Estados permanecem vinculados a sua legislação interna ou a instrumentos convencionais, mas que tampouco fornecem maiores esclarecimentos sobre a aplicação do princípio da precaução: tudo vai depender dos interesses em jogo, tendo em mente que a presunção de que os governos sempre agem no melhor interesse de seu povo deve ser afastada quando a situação envolve, sobretudo, os recursos naturais, conforme observa Okowa (apud Ebbensson, p. 20). 
Atualmente, a responsabilidade internacional do Estado em matéria de meio ambiente resume-se na obrigação de não causar danos graves ao território de outro Estado ou áreas fora de sua jurisdição, o que não representa nenhuma inovação da jurisprudência, eis que nada mais é do que a aplicação do princípio geral do não-dano formulado em 1949 pela CIJ no caso Corfu Channel ${ }^{33}$ e em outras decisões internacionais, ${ }^{34}$ como informa André Nollkaempter (2009, p. 255).

Porém, em matéria de proteção do meio ambiente ou da saúde pretende-se ir mais além, com a ímposição de obrigações concretas aos Estados para evitar que o dano ocorra efetivamente, sendo este, na maioria das vezes, irreparável e não suscetível de compensação financeira. Nesse aspecto, o princípio da precaução seria um dos mais eficientes princípios do direito internacional, embora tenhamos que reconhecer que permanece um princípio ainda em construção e que não conta com a ousadia dos tribunais internacionais, à exceção do ITLOS, para tentar galgar o status de norma costumeira internacional.

\section{Referências bibliográficas}

EBBENSSON Jonas (2009) "Introduction: dimensions of justice in environmental law”. In J. Ebbensson, e P. Okowa (coord). Environmental law and justice in context. Cambridge (UK): Cambridge University Press, pp. 1-36.

BRATSPIES Rebecca M. (2006) “Trail Smelter's (semi) precautionary legacy”. In R. Bratspies e R. Miller (org). Transboundary Harm in International Law: Lessons from the Trail Smelter Arbitration. New York: Cambridge University Press, pp. 153-166.

CRETELLA NETO José (2012) Curso de direito internacional do meio ambiente. São Paulo: Saraiva.

KISS Alexandre e SHELTON Dinah (2007) Guide to international environmental law. Leiden, The Netherlands: Koninklijke Brill NV.

McINTYRE Owe (2007) Environmental protection of international watercourses under international law. Hampshire (England): Ashgate Publishing Limited.

33 Corfu Channel case, Britain v. Albanian, ICJ Reports (1949). Disponível em: http://www. icj-cij.org/docket/files/1/1645.pdf

34 Trail Smelter Arbitration 1911, Advisory Opinion on the Legality of the Threat or Use of Nuclear Weapons (CIJ 1996); Gabcikovo-Nagymaros Project (CIJ 1997) e Pulp Mills on the River Uruguay (CIJ Request for Provisional Measures) 
NOLLKAEMPT André (2009) "Sovereignty and environmental justice in international law". In J. Ebbensson, e P. Okowa (coord). Environmental law and justice in context. Cambridge (UK): Cambridge University Press, pp. 253-269.

SCHRIJVER Nico (2008) The evolution of sustainable development in international law: Inception, meaning and status of sustainable development. Pocktbooks of the Hague Academy of International Law. The Hague: Martinus Nijhoff Publishers.

VITANYI Béla (1976) "La signification de la "généralité" dês príncipes de droit". Revue Générale de Droit International Public, Tome 80, pp. 536-545 